\title{
miR-21-5p promotes cell proliferation by targeting BCL11B in Thp-1 cells
}

\author{
LIANG ZHANG ${ }^{*}$, LI YU*, YIRAN LIU, SHASHA WANG, ZHENFENG HOU and JUN ZHOU \\ Shandong Provincial Key Laboratory of Animal Resistance Biology, Institute of Biomedical Sciences, \\ College of Life Sciences, Shandong Normal University, Jinan, Shandong 250014, P.R. China
}

Received December 10, 2019; Accepted November 3, 2020

DOI: $10.3892 / \mathrm{ol} .2020 .12380$

\begin{abstract}
Acute myeloid leukemia (AML) is a highly heterogeneous disease that remains untreatable. MicroRNAs (miRNAs or miRs) play important roles in the pathogenesis of leukemia. miR-21 is highly expressed in multiple types of human cancer and displays oncogenic activities; however, the clinical significance of miR-21 in AML remains unclear. In the present study, it was demonstrated that miR-21 levels were high in patients with AML and in AML cell lines. Further experiments demonstrated that overexpression of miR-21 in Thp-1 human monocytes derived from acute mononuclear leukemia peripheral blood promoted cell proliferation, while downregulation of miR-21-5p, a mature sequence derived from the 5 ' end of the miR-21 stem-loop precursor (another mature sequence, miR-21-3p, is derived form 3' end of miR-21), inhibited cell proliferation. Specifically, it was observed that overexpression of miR-21 could promote the transition of Thp-1 cells into the $\mathrm{S}$ and $\mathrm{G} 2 / \mathrm{M}$ phases of the cell cycle, as shown by flow cytometry. Furthermore, inhibition of miR-21-5p arrested cells in the $\mathrm{S}$ and G2/M phases. Finally, BCL11B was determined to be a functional target of $\mathrm{miR}-21-5 \mathrm{p}$ by luciferase assays Our study revealed functional and mechanistic associations between miR-21 and BCL11B in Thp-1 cells, which could serve to guide clinical treatment of AML.
\end{abstract}

\section{Introduction}

Acute myeloid leukemia (AML) is a heterogeneous disease that includes several discrete syndromes with characteristic clinical, morphological, phenotypic and cytogenetic features (1). According to the French-American-British (FAB) Co-operative

Correspondence to: Dr Liang Zhang, Shandong Provincial Key Laboratory of Animal Resistance Biology, Institute of Biomedical Sciences, College of Life Sciences, Shandong Normal University, 88 East Wenhua Road, Jinan, Shandong 250014, P.R. China

E-mail: zhangliang@sdnu.edu.cn

*Contributed equally

Key words: acute myeloid leukemia, Thp-1 monocytes, miR-21-5p, BCL11B
Group, the subgroups of AML defined in the FAB classification are M0, M1, M2, M3, M4, M5, M6 and M7 (2). For patients with AML under 60 years of age who undergo induction chemotherapy, complete remission (CR) rates of $60-70 \%$ are generally obtained, with a 5-year disease-free survival rate of $\leq 40 \%(3,4)$. By contrast, patients over 60 years of age have CR rates of $40-50 \%$, with a 3 -year disease-free survival rate of $<20 \%$ (5). Therefore, further characterization of the pathogenesis of AML is important for the development of new therapies.

As a type of antisense RNA, microRNAs (miRNAs or miRs) are a group of small noncoding RNAs of 22 nucleotides in length (6), which bind to complementary sites in the 3'-untranslated regions (3'-UTRs) of mRNA, and repress translation or induce mRNA degradation (7). Approximately $30 \%$ of all human protein-coding genes are regulated by miRNAs (8), and abnormally expressed miRNAs can function as tumor suppressors or oncogenes $(9,10)$. Increasingly, miRNAs have been evaluated in various types of cancer, and have been found to participate in the regulation of cancer cell behaviors, including proliferation, apoptosis, differentiation, metabolism and tumor metastasis (11-13). Notably, several aberrantly expressed tissue miRNAs have been regarded as diagnostic indicators in multiple cancer types (14-16).

Accumulating evidence has demonstrated that various miRNAs are closely associated with AML, including miR-9 (17), miR-21 (18), miR-34a (19), miR-126 (20), miR-143 (21) and miR-155 (22). Among them, miR-21, which is one of the best studied miRNAs, is highly expressed in numerous types of human cancer, including lung, cervical, colorectal, pancreatic and oral cancer (23-26), and displays oncogenic activities in various steps of tumorigenesis such as cell invasion, cell proliferation, metastasis and cell survival (27-29). Moreover, a meta-analysis summarizing the global predicting role of miR-21 for survival in patients with a variety of carcinomas in 2011 showed that elevated miR-21 expression is significantly associated with poor survival (30). Numerous miR-21 target genes have been identified, including phosphatase and tensin homolog deleted on chromosome ten (PTEN), programmed cell death 4 (PDCD4) and $\mathrm{B}$ cell translocation gene 2 , which play important roles in the oncogenic process $(23,28,31,32)$. In particular, several studies have investigated whether miR-21 is highly expressed in multiple types of leukemia such as chronic lymphocytic leukemia, chronic myelogenous leukemia, chronic myeloid 
leukemia, childhood B cell acute lymphoblastic leukemia and AML (32-36). In addition, a previous study demonstrated that miR-21 is overexpressed in nucleophosmin 1-mutant AML (36). These studies suggested that miR-21 may play an important role in AML progression. Recently, Li et al (18) reported that miR-21 promoted proliferation through directly regulating Kruppel-like factor 5 expression in AML cells. However, the detailed regulatory mechanisms of miR-21 in AML progression remain unknown.

B cell lymphoma/leukemia 11B (BCL11B) is a Krüppel-like $\mathrm{C} 2 \mathrm{H} 2$ zinc finger transcription factor located on chromosome $14 q 32.2$ that is required for normal T-cell development (37). Loss of BCL11B function in mice contributes to lymphomagenesis (38). BCL11B may have suppressive and disruptive effects on the proliferation and differentiation of myeloid cells (39).

miR-21 (miRBase Accession number: MI0000077), a stem-loop precursor sequence, is processed into two mature miRNA sequences, miR-21-5p (miRBase Accession number: MIMAT0000076) and miR-21-3p (miRBase Accession number: MIMAT0004494), are derived from 5' and 3' ends of miR-21, respectively (40). In the present study, it was demonstrated that miR-21 was highly expressed in patients with AML and in AML cell lines. Overexpression of miR-21 promoted the proliferation of Thp-1 cells, which derive from acute mononuclear leukemia peripheral blood, while downregulation of miR-21-5p (sequence: 5'-UAGCUUAUCAGACUGAUGUUGA-3') inhibited cell proliferation. Specifically, it was observed that overexpression of miR-21 could promote the entry of Thp-1 cells into the $S$ and $\mathrm{G} 2 / \mathrm{M}$ phases of the cell cycle, while inhibition of miR-21-5p arrested the cells in the $S$ and G2/M phases. In addition, BCL11B was identified as the functional target of miR-21-5p in Thp-1 cells. This study provides a novel insightful understanding of miR-21 in AML.

\section{Materials and methods}

The Cancer Genome Atlas (TCGA) dataset. miRNA and mRNA expression data, and clinical data for patients with AML, were obtained from TCGA data portal (http://cancergenome.nih.gov). Both the miRNA and mRNA expression data and clinical data, including the FAB subtype information of TCGA AML patients deposited at the Data Coordinating Center, are publicly available through open access. The present study meets the publication guidelines provided by TCGA (41). In total, data of 102 tumor samples were obtained, which were classified into six types (M0, M1, M2, M3, M4 and M5) according to their clinical data, excluding subtypes with low number of cases such as M6 $(n=1)$ and M7 $(n=2)$. The miRNA and mRNA expression data from 99 cases were available and included in the datasets from the platforms. All datasets were processed and calculated for kilo reads per million (KRPM).

Cell culture. Human bone marrow stromal HS-5 cells and human leukemia cell lines, including HL-60, NB4 and Thp-1, were purchased from American Type Culture Collection. Mycoplasma testing was performed on all the cell lines used. The cells were maintained in RPMI-1640 culture medium (Gibco; Thermo Fisher Scientific, Inc.) containing 10\% fetal bovine serum (Gibco; Thermo Fisher Scientific, Inc.), and $2 \mathrm{mM}$ L-glutamine and $1 \%$ penicillin-streptomycin solution
$(10,000 \mathrm{U} / \mathrm{ml}$ penicillin and $10 \mathrm{mg} / \mathrm{ml}$ streptomycin, HyClone; GE Healthcare Life Sciences) at $37^{\circ} \mathrm{C}$ in $5 \% \mathrm{CO}_{2}$.

Lentivirus infection. Lentiviral vectors expressing hsa-miR-21 (LV-miR-21) and hsa-miR-21-5p-inhibitor (LV-miR-21-5p inhibitor), as well as a control vector (LV-control), were constructed by Shanghai GeneChem Co., Ltd. For lentivirus-mediated miR-21, miR-21-5p-inhibitor or control vector transfection in vitro, $1.0 \times 10^{5}$ cells $/ \mathrm{ml} \mathrm{Thp}-1$ cells were infected with a lentivirus at a multiplicity of infection of 50 in the presence of polybrene ( $5 \mu \mathrm{g} / \mathrm{ml}$; Sigma-Aldrich; Merck KGaA). After 8-12 h of infection, the culture media containing lentiviruses was removed after centrifugation at $300 \mathrm{x} g$ for $5 \mathrm{~min}$ at room temperature, and the cells were incubated with RPMI-1640 complete culture media for additional 48-72 h. Next, the cells were screened with $2 \mu \mathrm{g} / \mathrm{ml}$ puromycin to obtain stable cell lines for subsequent experiments.

Cell proliferation assay. MTT assay was used to evaluate cell proliferation. Normal Thp-1 cells, as well as cells transfected with LV-miR-21, LV-miR-21-5p inhibitor and LV-control, were plated in a 96 -well plate at a density of $1.5 \times 10^{4}$ cells/well. After 24 or 48 h, $20 \mu \mathrm{l}$ MTT solution $(5 \mathrm{mg} / \mathrm{ml}$, Sigma-Aldrich; Merck KGaA) was added to each well, and the cells were cultured for $4 \mathrm{~h}$. Subsequently, $200 \mu \mathrm{l}$ DMSO was added to each well, and the absorbance was measured at $492 \mathrm{~nm}$ with a microplate reader (Multiskan Ascent; Thermo Fisher Scientific, Inc.).

Cell cycle assay. Flow cytometry was used to conduct cell cycle analysis. Normal Thp-1 cells, as well as cells transfected with LV-miR-21, LV-miR-21-5p inhibitor and LV-control, that were in the exponential phase of cell proliferation were centrifuged at $1,000 \mathrm{x} \mathrm{g}$ for $5 \mathrm{~min}$ at room temperature, and the cell pellets were harvested. Next, the cells were washed once with PBS for 2 min and fixed in $70 \%$ ethanol overnight at $4^{\circ} \mathrm{C}$. Subsequently, the cells were washed with PBS and treated with $0.1 \mathrm{mg} / \mathrm{ml}$ RNase A (Sigma-Aldrich; Merck KGaA) at $37^{\circ} \mathrm{C}$ for $30 \mathrm{~min}$. Finally, the cells were stained with propidium iodide (Sigma-Aldrich; Merck $\mathrm{KGaA}$ ) at $4^{\circ} \mathrm{C}$ for $30 \mathrm{~min}$ in the dark. Fluorescence was then detected with a FACS 420 system (BD Biosciences) at $488 \mathrm{~nm}$. ModFit 3.0 software (BD Biosciences) was used to analyze the DNA content.

Reverse transcription-quantitative PCR (RT-qPCR). Total RNA was extracted from Thp-1 cells with TRIzol ${ }^{\circledR}$ reagent (Thermo Fisher Scientific, Inc.). RT-qPCR for miRNA analysis was performed with cDNA, which was generated from $1 \mu \mathrm{g}$ total RNA using the All-in-One ${ }^{\mathrm{TM}}$ miRNA First-Strand cDNA Synthesis Kit (GeneCopoeia, Inc.) and a miRNA RT-qPCR detection kit (GeneCopoeia, Inc.). RT-qPCR analysis was performed using the U6 gene as an internal control for normalization and the LightCycler ${ }^{\circledR} 96$ Real-Time PCR System (Roche Diagnostics) with the following conditions: A heating step at $95^{\circ} \mathrm{C}$ for $10 \mathrm{~min}$, followed by 40 cycles of $95^{\circ} \mathrm{C}$ for $10 \mathrm{sec}, 60^{\circ} \mathrm{C}$ for $20 \mathrm{sec}$ and $72^{\circ} \mathrm{C}$ for $20 \mathrm{sec}$. PCR specificity was checked by melting curve analysis. The primers against mature miRNA hsa-miR-21-3p (cat. no. HmiRQP0315), hsa-miR-21-5p (cat. no. HmiRQP0316), and U6 (cat. no. HmiRQP9001) were purchased from GeneCopoeia, Inc. All reactions were 
conducted in triplicate, and the $2^{-\Delta \Delta \mathrm{Cq}}$ method (42) was used to quantify the level of miRNA expression.

Western blot analysis. Western blot analysis was carried out to detect the protein expression of proliferating cell nuclear antigen (PCNA), BCL11B and murine doubleminute 2 (MDM2) in normal Thp-1 cells, as well as cells transfected with LV-miR-21, LV-miR-21-5p inhibitor and LV-control. Cells were lysed in RIPA lysis buffer (Beyotime Institute of Biotechnology) on ice. The cellular debris was discarded by centrifugation at $4^{\circ} \mathrm{C}$ and $12,000 \mathrm{x}$ g for $15 \mathrm{~min}$. BCA Protein Assay Kit (Beyotime Institute of Biotechnology) was used to measure the protein concentration of the supernatants. Protein samples (30 $\mu \mathrm{g}$ per lane) were separated on $12 \%$ SDS-PAGE and then transferred to polyvinylidene difluoride membranes. The membranes were blocked with $5 \%$ skim milk for $1.5 \mathrm{~h}$ at room temperature and then incubated overnight at $4{ }^{\circ} \mathrm{C}$ with primary antibodies against PCNA (monoclonal rabbit anti-human, cat. no. ab92552; 1:1,000; Abcam), BCL11B (monoclonal rabbit anti-human, cat. no. ab240636; 1:1,000; Abcam), MDM2 (monoclonal rabbit anti-human, cat. no. ab259265; 1:1,000; Abcam) and GAPDH (monoclonal rabbit anti-human, cat. no. ab181602; 1:1,000; Abcam), which served as a loading control. Membranes were washed three times for ten minutes each with Tris-buffered saline containing $0.1 \%(\mathrm{v} / \mathrm{v})$ Tween-20 (TBS-T), then were incubated withHRP-labeled goat anti-rabbit IgG (cat. no. 111-035-003; 1:10,000; Jackson ImmunoResearch Laboratories, Inc.) for $1.5 \mathrm{~h}$ at room temperature. After washing three times for ten minutes each with TBS-T, the bound antibodies were detected using enhanced chemiluminescence reagents (Beyotime Institute of Biotechnology) and visualized by a ChemiDoc-It Imaging System (Analytik Jena AG). The image density of the immunoblots was determined by Image Pro-Plus 6.0 software (Media Cybernetics, Inc.).

Bioinformatic analysis of $m i R-21-5 p$ target genes. Putative miR-21-5p targets were predicted using different algorithms, including miRanda (http://www.miranda.org) and TargetScan Release 7.2 (http://www.targetscan.org/vert_72). The miRNA-target interactions and sequence conservation were analyzed with TargetScan.

Dual-luciferase reporter assay. 293 cells were obtained from The Cell Bank of Type Culture Collection of The Chinese Academy of Sciences, and were cultured in Dulbecco's modified Eagle's medium (Gibco; Thermo Fisher Scientific, Inc.) at $37^{\circ} \mathrm{C}$ with $5 \% \mathrm{CO}_{2}$. Cells were plated in a 96-well plate at a density of $1.5 \times 10^{4}$ cells/well. A psiCHECK-2 reporter vector (Promega Corporation) containing the wild-type (WT) 3'-UTR or the random mutations (MUT) of BCL11B were co-transfected with miR-21-5p mimic, miR-21-5p inhibitor or a negative control (NC) (Shanghai GenePharma Co., Ltd.) at a concentration of $50 \mathrm{nM}$ into 293 cells using Lipofectamine ${ }^{\circledR} 2000$ reagent (Thermo Fisher Scientific, Inc.). After $48 \mathrm{~h}$, the firefly and Renilla luciferase activities were detected by a Lumat LB9507 luminometer (Titertek-Berthold) using a Dual-Luciferase Reporter Assay System (Promega Corporation) according to the manufacturer's protocol. The relative luciferase activity was calculated as the ratio of Renilla signal/firefly signal.
A
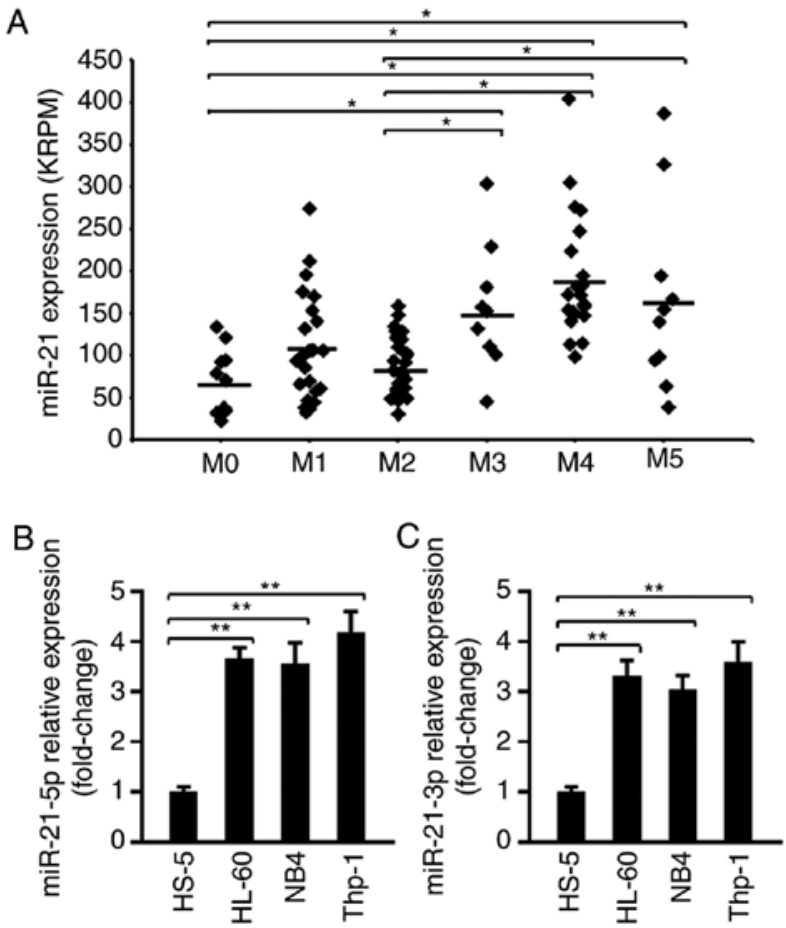

Figure 1. miR-21 is highly expressed in patients with AML and in AML cell lines. (A) The expression of miR-21 in patients with AML from The Cancer Genome Atlas data portal was analyzed. A total of 102 tumor samples were classified into six types (M0, M1, M2, M3, M4 and M5) according to their clinical data. All datasets were processed and calculated for KRPM. "P<0.05. (B) The relative expression of miR-21-5p in the human bone marrow stromal cell line HS-5 and in three human AML cell lines (HL-60, NB4 and Thp-1) was determined by RT-qPCR $(n=5) .{ }^{* *} \mathrm{P}<0.01$. (C) The relative expression of miR-21-3p in HS-5, HL-60, NB4 and Thp-1 cells was determined by RT-qPCR $(\mathrm{n}=5) .{ }^{* *} \mathrm{P}<0.01$. AML, acute myeloid leukemia; miR, microRNA; RT-qPCR, reverse transcription-quantitative PCR; KRPM, kilo reads per million.

Statistical analysis. All experiments were performed at least in triplicate. The experimental data are expressed as the mean \pm standard deviation. SPSS software version 18.0 (SPSS, Inc.) was used to perform statistical analyses. Differences among groups were evaluated by one-way ANOVA followed by Tukey's post-hoc test. Statistical analyses between two groups were evaluated with Student's t-test. Two-sided $\mathrm{P}<0.05$ was considered to indicate a statistically significant difference.

\section{Results}

miR-21 is expressed at high levels in patients with AML and in AML cell lines. miR-21 expression was analyzed in TCGA samples from 103 patients with AML. First, based on the patient information, the data were classified as M0-M5 according to the FAB criteria, and the expression levels of miR-21 in these samples were compared. As shown in Fig. 1A, miR-21 expression was significantly higher in M3, M4 and M5 than in M0, M1 and M2. No differences were observed among the subgroups M3, M4 or M5. Additionally, the levels of miR-21-3p and miR-21-5p in various cell lines were examined. Human bone marrow stromal HS-5 cells were selected as normal control cells. The RT-qPCR results showed that the levels of miR-21-5p and miR-21-3p were significantly upregulated in the Thp-1, HL-60 and NB4 cell lines compared 
A
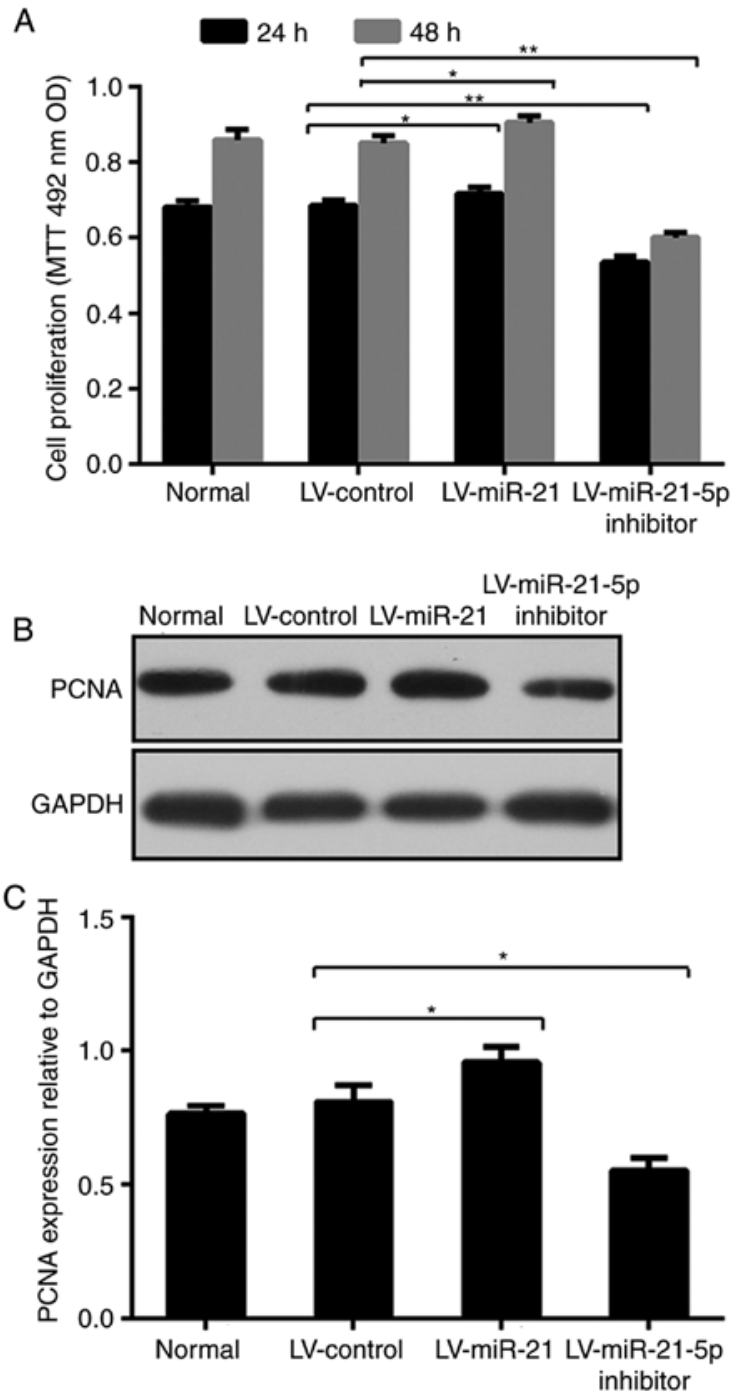

Figure 2. miR-21 promotes cell proliferation. (A) Cell proliferation was detected with MTT assays. Thp-1 cells were infected with LV-miR-21, LV-miR-21-5p inhibitor and LV-control, respectively $(\mathrm{n}=5)$. ${ }^{*} \mathrm{P}<0.05$, ${ }^{* *} \mathrm{P}<0.01$. (B) PCNA protein expression, as analyzed by western blotting. (C) The western blots were quantified and presented as the PCNA/GAPDH ratio $(n=3)$. $P<0.05$. miR, microRNA; $L V$, lentivirus; PCNA, proliferating cell nuclear antigen.

with their expression levels in HS-5 cells (Fig. 1B and C), suggesting that miR-21 was expressed at high levels in AML cell lines. Of note, Thp-1 cells appeared to exhibit the highest miR-21 expression; therefore, the AML cell line Thp-1 was selected for subsequent in vitro experiments.

miR-21-5p significantly promotes Thp-1 cell proliferation. To investigate the biological function of miR-21, human Thp-1 cell lines that stably overexpressed miR-21 (LV-miR-21), miR-21-5p inhibitor (LV-miR-21-5p inhibitor) or NC (LV-control) were constructed. As shown in Fig. S1, the expression of miR-21-3p and miR-21-5p was markedly upregulated in cells infected with LV-miR-21, while miR-21-5p, not miR-21-3p, was significantly downregulated in cells infected with LV-miR-21-5p inhibitor, suggesting that miR-21 overexpression and miR-21-5p inhibition were successful in Thp-1 cells.

To evaluate the proliferation of normal cells and cells transfected with LV-miR-21, LV-miR-21-5p inhibitor or
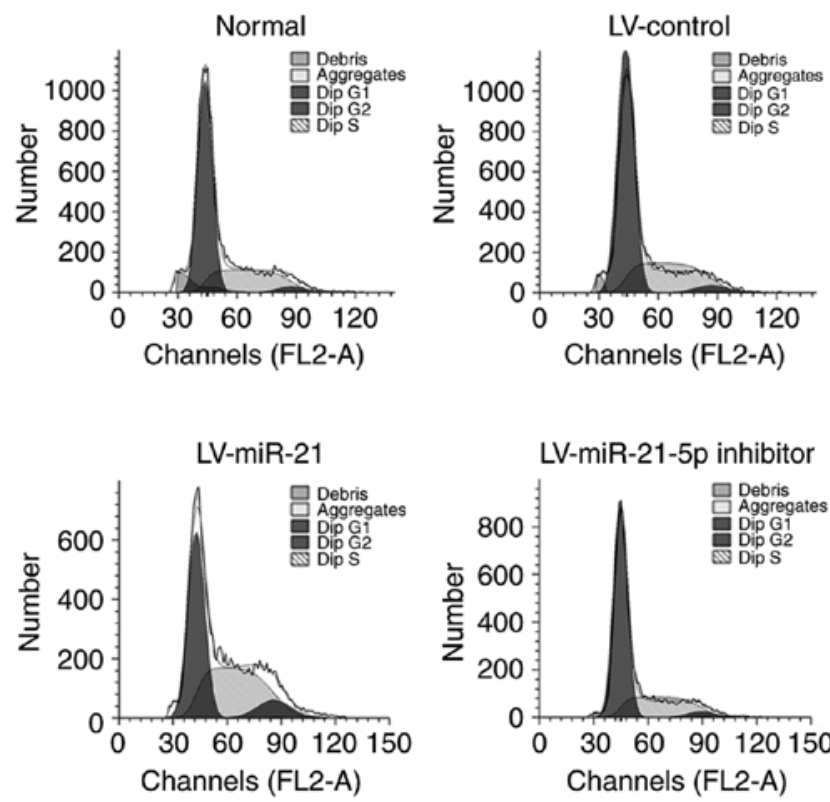

Figure 3. miR-21 effects on the cell cycle distribution of Thp-1 cells. Cells were cultured in RPMI-1640 medium. Once the cells had been fixed and stained with propidium iodide, their DNA content was measured by flow cytometry. Cell cycle distribution was analyzed with ModFit software. miR microRNA; LV, lentivirus; Dip, diploid.

LV-control, an MTT assay was performed. As presented in Fig. 2A, the proliferation of cells transfected with LV-miR-21-5p inhibitor was obviously reduced compared with that of cells transfected with LV-control at $24 \mathrm{~h}$ $(0.684 \pm 0.014$ and $0.535 \pm 0.014)$ and $48 \mathrm{~h}(0.856 \pm 0.025$ and $0.601 \pm 0.012)$, respectively. Unlike that of cells transfected with LV-miR-21-5p inhibitor, the proliferation of cells transfected with LV-miR-21 was significantly higher compared with that of LV-control cells at 24 and $48 \mathrm{~h}$, indicating that miR-21-5p promoted Thp-1 cell proliferation.

PCNA, a nuclear antigen in proliferating cells, protein levels peak during the $\mathrm{S}$ phase of the cell cycle (43). PCNA is almost undetectable in other phases of the cycle. Due to its unique expression, PCNA has been extensively used in studies associating the prognosis of tumor progression and neoplastic proliferation (44-46). Therefore, the expression of PCNA was investigated by western blotting in the present study. As observed in Fig. 2B and C, and consistent with the cell proliferation assay, the PCNA protein levels were substantially increased in Thp-1 cells after transfection with LV-miR-21, whereas transfection with LV-miR-21-5p inhibitor reversed such increase. Collectively, these data suggested that miR-21-5p promoted Thp-1 cell proliferation.

miR-21-5p promotes the transition of Thp-1 cells into the proliferative phases of the cell cycle. To explore the possible mechanism by which miR-21 promotes the proliferation of Thp-1 cells, the distribution of cells within the different stages of the cell cycle was determined by flow cytometry. As shown in Table I and Fig. 3, compared with that of LV-control cells, the proportion of cells transfected with LV-miR-21 in the G0/G1 phase was remarkably reduced by $17.0 \%$, while it was increased by $\sim 22.5 \%$ in cells transfected with LV-miR-21-5p inhibitor. The proportion of cells transfected with miR-21 in the $S$ phase was significantly increased by $15.9 \%$ compared with that 
A
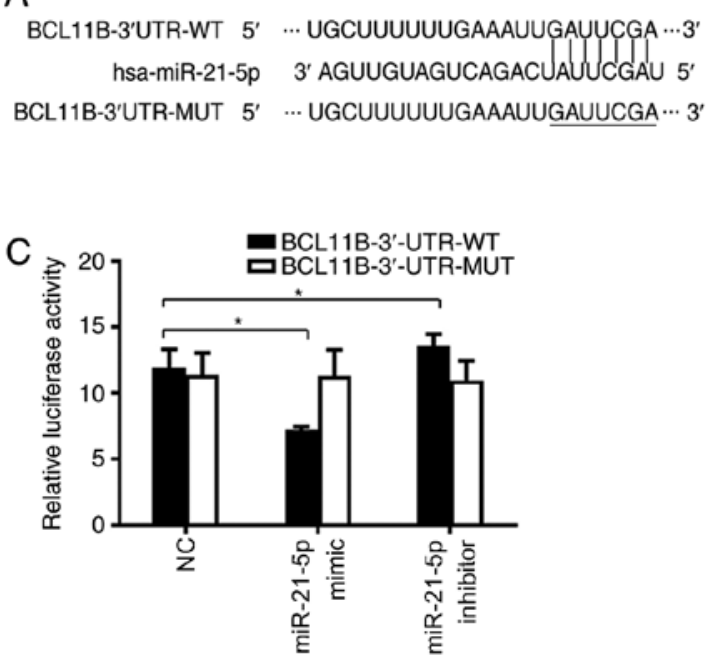

D
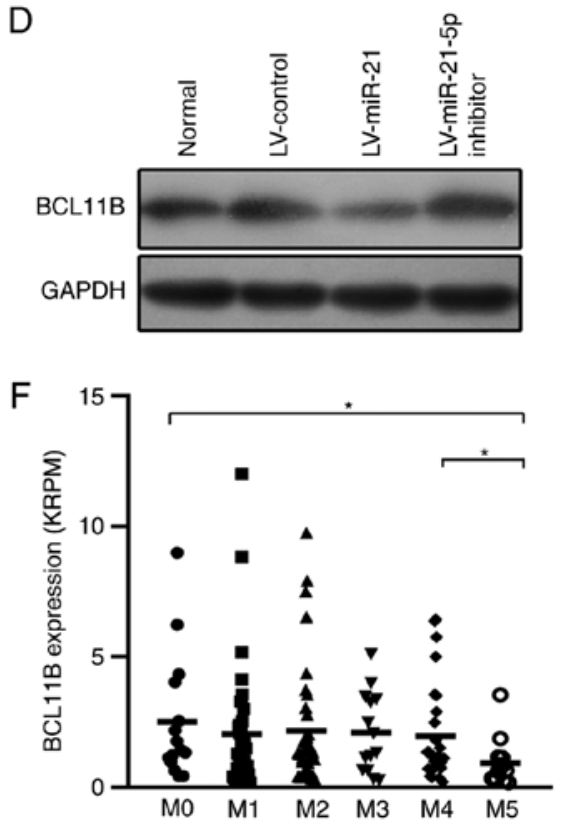

B

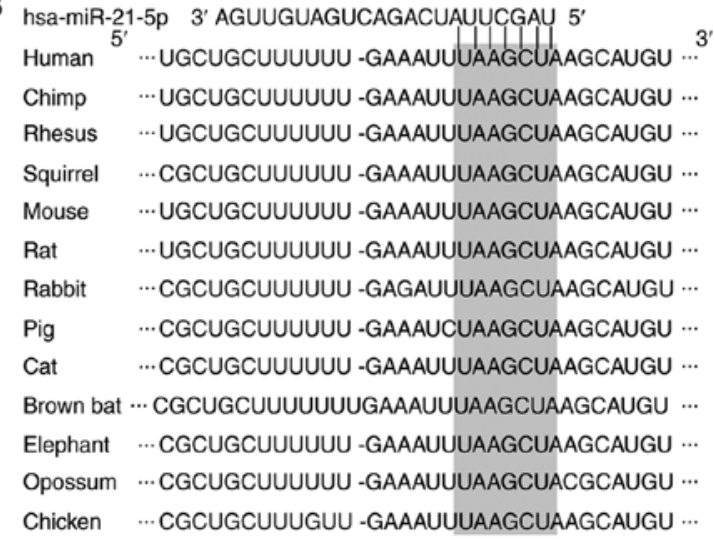

E

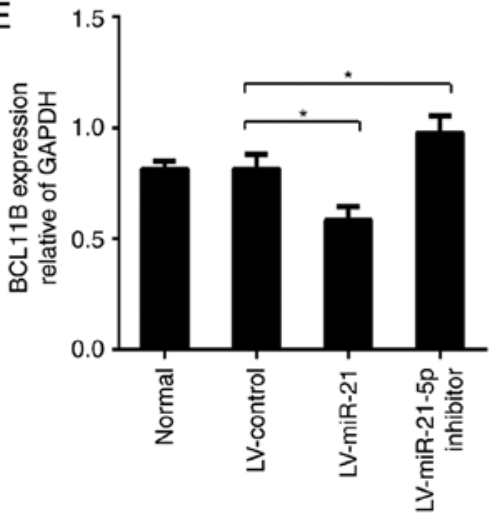

Figure 4. BCL11B is a direct target of miR-21-5p. (A) Schematic representation of the miR-21-5p putative binding site in the human BCL11B 3'-UTR, and alignment of the WT and MUT BCL11B 3'-UTR binding site of miR-21-5p. The BCL11B mutated nucleotides are underlined. (B) The conserved miR-21-5p binding site in the BCL11B 3'-UTR is shown in grey. (C) 293 cells were co-transfected with a luciferase reporter carrying BCL11B-3'-UTR-WT or BCL11B-3'-UTR-MUT, together with miR-21-5p mimic, miR-21-5p inhibitor or a negative control. Luciferase activities were measured at $48 \mathrm{~h}$ after transfection $(\mathrm{n}=5)$. ${ }^{\mathrm{P}} \mathrm{P}$ 0.05. (D) BCL11B protein expression was analyzed in Thp-1 normal cells, and in LV-miR-21, LV-miR-21-5p inhibitor and LV-control cells by western blotting. (E) The blots were quantified with Image Pro-Plus 6.0 software, and the results are represented as the BCL11B/GAPDH ratio (n=3). $\mathrm{P}<0.05$. (F) The expression of BCL11B in patients with acute myeloid leukemia from The Cancer Genome Atlas data portal was analyzed. All datasets were processed and calculated for KRPM. "P<0.05. miR, microRNA; LV, lentivirus; WT, wild-type; MUT, mutant; UTR, untranslated region; NC, negative control; KRPM, kilo reads per million; BCL11B, B-cell lymphoma/leukemia 11B.

Table I. Percentage of cells in cell cycle phases by flow cytometry (mean \pm standard deviation).

\begin{tabular}{lccc}
\hline Group & G0/G1 & \multicolumn{1}{c}{$\mathrm{S}$} & G2/M \\
\hline Normal & $59.69 \pm 1.12$ & $35.57 \pm 1.36$ & $4.75 \pm 0.94$ \\
LV-control & $55.08 \pm 0.18$ & $39.38 \pm 0.28$ & $5.54 \pm 0.10$ \\
LV-miR-21 & $45.71 \pm 0.13^{\mathrm{a}}$ & $45.63 \pm 0.45^{\mathrm{a}}$ & $8.67 \pm 0.30^{\mathrm{b}}$ \\
LV-miR-21-5p & $67.48 \pm 0.18^{\mathrm{a}}$ & $28.82 \pm 0.27^{\mathrm{a}}$ & $3.70 \pm 0.08^{\mathrm{a}}$ \\
inhibitor & & &
\end{tabular}

${ }^{\mathrm{a}} \mathrm{P}<0.01$ vs. $\mathrm{LV}$-control ( $\left.\mathrm{n}=5\right)$; ${ }^{\mathrm{b}} \mathrm{P}<0.05$ vs. $\mathrm{LV}$-control ( $\left.\mathrm{n}=3\right)$; $\mathrm{LV}$, lentivirus. of the LV-control group, while it was reduced by $\sim 26.8 \%$ in cells transfected with LV-miR-21-5p inhibitor. The proportion of LV-miR-21 cells in the G2/M phase increased by $\sim 56.5 \%$ compared with that of the LV-control group, whereas it decreased by $\sim 33.2 \%$ in LV-miR-21-5p inhibitor-transfected cells. Together, these results indicated that overexpression of miR-21-5p promoted the transition of Thp-1 cells into the proliferative phases of the cell cycle (as indicated by the proportion of cells in the $\mathrm{S}$ and $\mathrm{G} 2 / \mathrm{M}$ phases), while inhibition of miR-21-5p arrested cells in the $\mathrm{S}$ and G2/M phases.

$B C L 11 B$ is the direct target gene of miR-21-5p. To determine the underlying mechanisms by which miR-21-5p contributes to 


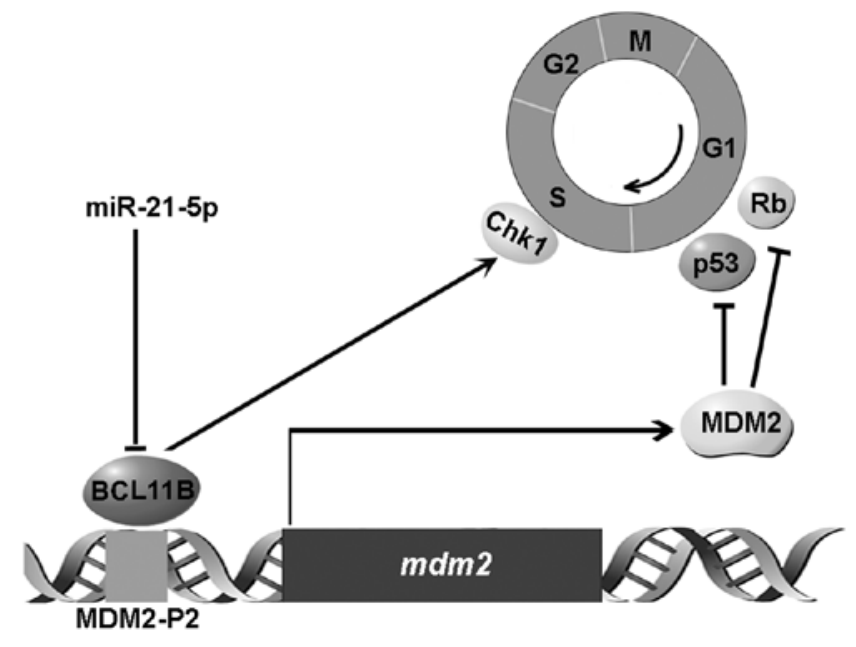

Figure 5. Schematic representation of the pathway modulated by miR-21 in Thp-1 cells progressing through the cell cycle. miR-21-5p targets BCL11B, which might modulate the cell cycle effectors Chk1 and MDM2. BCL11B binds to the human MDM2-P2 promoter and inhibits MDM2 expression. MDM2 inhibits the tumor suppressor proteins $\mathrm{p} 53$ and $\mathrm{Rb}$, which promotes cell arrest in the G1 phase. Besides, BCL11B promotes the activation of the cell cycle checkpoint kinase Chk1, which leads to arrest of the cell cycle at the $\mathrm{S}$ phase by Cdc25A phosphorylation. miR, microRNA; BCL11B, B-cell lymphoma/leukaemia 11B; $\mathrm{Rb}$, retinoblastoma protein; Chk1, checkpoint kinase 1; MDM2, murine doubleminute 2.

AML, the bioinformatic algorithms miRanda and TargetScan were used to predict the potential target genes of miR-21-5p. According to the prediction analysis, BCL11B, an important transcriptional regulator and a tumor suppressor gene (47), has a putative miR-21-5p-binding site (Fig. 4A). The target sequence is highly conserved across species, including human, chimp, rhesus, squirrel, mouse, rat, rabbit and pig (Fig. 4B). To validate the miRNA-target interactions, the 3'-UTR sequence of BCL11B containing the putative binding site of miR-21-5p was cloned into the psiCHECK-2 reporter vector. The constructed vector was then co-transfected with miR-21-5p mimic, miR-21-5p inhibitor or NC into 293 cells. As shown in Fig. S2, the expression of miR-21-5p was markedly upregulated in cells transfected with miR-21-5p mimic, and significantly downregulated in cells transfected with miR-21-5p inhibitor, suggesting that miR-21-5p overexpression and inhibition were successful. As presented in Fig. 4C, the transfection of miR-21-5p mimic suppressed the luciferase activity, while miR-21-5p inhibitor increased the activity of the WT-BCL11B reporter compared with that of the NC. No significant change was observed in the luciferase activity of the MUT-BCL11B reporter between the miR-21-5p mimic and miR-21-5p inhibitor groups, suggesting that BCL11B is a direct target gene of miR-21-5p.

Furthermore, western blotting was performed to determine whether miR-21-5p influenced the expression level of BCL11B in Thp-1 cells. As revealed in Fig. 4D and E, the expression of BCL11B protein was remarkably decreased after overexpression of miR-21-5p; however, it was significantly increased in LV-miR-21-5p inhibitor-transfected cells. The expression of BCL11B was further analyzed in patients with AML from TCGA dataset. The results showed that the expression of BCL11B in patients with FAB M5 was significantly decreased compared with that of patients with M0 and M4. No differences were observed among other subgroups (Fig. 4F). Together, these results suggested that miR-21-5p suppressed BCL11B expression by directly targeting its 3'-UTR in Thp-1 cells.

\section{Discussion}

The current study aimed to investigate the role of miR-21 in AML cell proliferation and to explore its possible mechanisms. It was found that miR-21 was expressed at high levels in patients with AML and in AML cell lines. Further experiments indicated that overexpression of miR-21 in Thp-1 cells promoted proliferation, while downregulation of miR-21-5p inhibited proliferation. Specifically, it was observed that overexpression of miR-21 could promote Thp-1 cell transition into the $\mathrm{S}$ and $\mathrm{G} 2 / \mathrm{M}$ phases of the cell cycle, as shown by flow cytometry, while inhibition of miR-21-5p arrested cells in the $\mathrm{S}$ and $\mathrm{G} 2 / \mathrm{M}$ phases. Finally, BCL11B was identified as a functional target of miR-21-5p by luciferase assays.

miR-21 has been reported to be an oncogene, and to be upregulated in various human cancer types such as glioblastoma, and prostate, breast, pancreas, esophagus and liver cancer (29,48-50). Additionally, miR-21 is also highly expressed in various types of blood cancer (51-54). Furthermore, several targets of miR-21 have been identified, including PDCD4 (27), myristoylated alanine-rich C-kinase substrate (49) and leucine-rich repeat (in FLII) interacting protein 1 (48). Previous studies have indicated that miR-21 promotes the proliferation and growth of hepatocellular carcinoma cells by targeting PTEN, which activates the AKT signaling pathway (55). However, there are limited reports on the function and targets of miR-21 in AML. The present study showed that BCL11B is the direct target gene of miR-21-5p in Thp-1 cells.

The BCL11 family has two members, BCL11A and BCL11B. BCL11A is a zinc finger protein that is critically involved in the normal differentiation of lymphocytes (56), while BCL11B is a Krüppel-like $\mathrm{C} 2 \mathrm{H} 2$ zinc finger transcription factor that is required for normal T-cell development (37). Abbas et al (39) reported that BCL11B may have suppressive and disruptive effects on the proliferation and differentiation of myeloid cells. Loss of BCL11B was demonstrated to cause a natural killer cell-like phenotype with differentiation arrest, and was linked to a high proliferative potential. Mechanistically, BCL11B binds to the GC-rich consensus sequence of target genes, and/or interacts with the nucleosome remodeling and histone deacetylase complex, thus repressing the transcription of target genes (57). Previous studies have found that BCL11B binds to the $\mathrm{P} 2$ promotor of human double minute 2 promoter and inhibits HDM2 expression in a p53-dependent manner (47). HDM2, also known as MDM2, is an oncogene that encodes a nucleus-localized E3 ubiquitin ligase that can promote tumor formation by targeting tumor suppressor proteins such as p53. Activated p53 regulates multiple p53 target genes, which results in various cellular responses, including apoptosis, cell cycle arrest and DNA repair (58). In addition, MDM2 also has p53-independent oncogenic functions, including control of proliferation, apoptosis and tumor invasion. For example, MDM2 can interact with the tumor suppressor retinoblastoma protein, which is a negative regulator of the cell cycle, thus inhibiting its function in the regulation of the cell cycle and proliferation (59). In our study, the MDM2 protein levels in LV-miR-21, LV-miR-21-5p inhibitor and LV-control cells were 
analyzed. As shown in Fig. S3, the expression of MDM2 was remarkably increased after overexpression of miR-21; however, it was significantly decreased in LV-miR-21-5p inhibitor-transfected cells, suggesting that miR-21 targets BCL11B and then regulates the expression of MDM2. Another study showed that the expression of the $\mathrm{CDK}$ inhibitor p27 was decreased in BCL11B-knockdown Jurkat cells, which are a type of T-cell line used for studying the regulatory role of BCL11B in the cell cycle. A decrease in p27 may promote cell cycle progression during the $S$ phase (60). In addition, in BCL11B-knockdown cells, the activation of the cell cycle checkpoint kinase Chk1 was deregulated, and activated Chk1 led to the arrest of the cell cycle at the $\mathrm{S}$ phase by Cdc25A phosphorylation (61). The present study confirmed that miR-21-5p regulated the expression of BCL11B. In AML cells, downregulated expression of BCL11B may influence the process of cell proliferation by changing the expression of MDM2 or a CDK inhibitor, or by regulating the activation of Chk1. The exact mechanism is not entirely clear yet.

In conclusion, our study demonstrated that miR-21 was expressed at high levels in patients with AML and in AML cell lines. Functional and mechanistic studies suggested that miR-21-5p promoted Thp-1 cell proliferation (as indicated by the proportion of cells in the $S$ and $G 2 / M$ phases of the cell cycle) by targeting BCL11B. The present study provides a new insight into the mechanisms of AML, and suggests that miR-21 might be a potential AML therapeutic target.

\section{Acknowledgements}

Not applicable.

\section{Funding}

This work was supported by the National Natural Science Foundation of China (grant nos. 81100193 and 31871441) and the Shandong Provincial Natural Science Foundation (grant no. ZR2017MH087).

\section{Availability of data and materials}

The datasets generated and analyzed during the study are available from the corresponding author on reasonable request.

\section{Authors' contributions}

LZ and LY conducted the cell culture and cell proliferation experiments, as well as the cell cycle analyses, and were major contributors in writing the manuscript. YL and SW conducted the RT-qPCR and western blot experiments, and performed the statistical analyses. ZH analyzed TCGA data and revised the manuscript. JZ contributed to the study design. All authors read and approved the final version of the manuscript.

\section{Ethics approval and consent to participate}

Not applicable.

\section{Patient consent for publication}

Not applicable.

\section{Competing interests}

The authors declare that they have no competing interests.

\section{References}

1. Vandenberghe H; Second MIC Cooperative Study Group: Morphologic, immunologic and cytogenetic (MIC) working classification of the acute myeloid leukaemias. Br J Haematol 68: 487-494, 1988

2. Head DR: Revised classification of acute myeloid leukemia. Leukemia 10: 1826-1831, 1996.

3. Ravindranath Y, Chang M, Steuber CP, Becton D, Dahl G, Civin C, Camitta B, Carroll A, Raimondi SC and Weinstein HJ; Pediatric Oncology Group: Pediatric Oncology Group (POG) studies of acute myeloid leukemia (AML): A review of four consecutive childhood AML trials conducted between 1981 and 2000. Leukemia 19: 2101-2116, 2005.

4. Smith FO, Alonzo TA, Gerbing RB, Woods WG, Arceci RJ and Grp Cs C; Children's Cancer Group: Long-term results of children with acute myeloid leukemia: a report of three consecutive Phase III trials by the Children's Cancer Group: CCG 251, CCG 213 and CCG 2891. Leukemia 19: 2054-2062, 2005.

5. Estey EH: How I treat older patients with AML. Blood 96: 1670-1673, 2000.

6. Cummins JM and Velculescu VE: Implications of micro-RNA profiling for cancer diagnosis. Oncogene 25: 6220-6227, 2006.

7. Bartel DP: MicroRNAs: Target recognition and regulatory functions. Cell 136: 215-233, 2009.

8. Filipowicz W, Bhattacharyya SN and Sonenberg N: Mechanisms of post-transcriptional regulation by microRNAs: Are the answers in sight? Nat Rev Genet 9: 102-114, 2008.

9. Calin GA and Croce CM: MicroRNA signatures in human cancers. Nat Rev Cancer 6: 857-866, 2006.

10. Kumar MS, Lu J, Mercer KL, Golub TR and Jacks T: Impaired microRNA processing enhances cellular transformation and tumorigenesis. Nat Genet 39: 673-677, 2007.

11. Croce CM and Calin GA: miRNAs, cancer, and stem cell division. Cell 122: 6-7, 2005.

12. Bartel DP: MicroRNAs: Genomics, biogenesis, mechanism, and function. Cell 116: 281-297, 2004.

13. Gregory RI and Shiekhattar R: MicroRNA biogenesis and cancer. Cancer Res 65: 3509-3512, 2005.

14. Silakit R, Loilome W, Yongvanit P, Chusorn P, Techasen A, Boonmars T, Khuntikeo N, Chamadol N, Pairojkul C and Namwat N: Circulating miR-192 in liver fluke-associated cholangiocarcinoma patients: A prospective prognostic indicator. J Hepatobiliary Pancreat Sci 21: 864-872, 2014.

15. Wang LG and Gu J: Serum microRNA-29a is a promising novel marker for early detection of colorectal liver metastasis. Cancer Epidemiol 36: e61-e67, 2012.

16. Ng EKO, Chong WWS, Jin H, Lam EK, Shin VY, Yu J, Poon TC, Ng SS and Sung JJ: Differential expression of microRNAs in plasma of patients with colorectal cancer: A potential marker for colorectal cancer screening. Gut 58: 1375-1381, 2009.

17. Chen P, Price C, Li Z, Li Y, Cao D, Wiley A, He C, Gurbuxani S, Kunjamma RB, Huang H, et al: miR-9 is an essential oncogenic microRNA specifically overexpressed in mixed lineage leukemia-rearranged leukemia. Proc Natl Acad Sci USA 110: 11511-11516, 2013.

18. Li C, Yan H, Yin J, Ma J, Liao A, Yang S, Wang L, Huang Y, Lin C, Dong Z, et al: MicroRNA-21 promotes proliferation in acute myeloid leukemia by targeting Krüppel-like factor 5. Oncol Lett 18: 3367-3372, 2019.

19. Liu L, Ren W and Chen K: MiR-34a promotes apoptosis and inhibits autophagy by targeting HMGB1 in acute myeloid leukemia cells. Cell Physiol Biochem 41: 1981-1992, 2017.

20. de Leeuw DC, Denkers F, Olthof MC, Rutten AP, Pouwels W, Schuurhuis GJ, Ossenkoppele GJ and Smit L: Attenuation of microRNA-126 expression that drives $\mathrm{CD}^{3} 4^{+} 38^{-}$stem/progenitor cells in acute myeloid leukemia leads to tumor eradication. Cancer Res 74: 2094-2105, 2014.

21. Hartmann JU, Brauer-Hartmann D, Kardosova M, Wurm AA, Wilke F, Schödel C, Gerloff D, Katzerke C, Krakowsky R, Namasu CY, et al: MicroRNA-143 targets ERK5 in granulopoiesis and predicts outcome of patients with acute myeloid leukemia. Cell Death Dis 9: 814, 2018. 
22. Wallace JA, Kagele DA, Eiring AM, Kim CN, Hu R, Runtsch MC Alexander M, Huffaker TB, Lee SH, Patel AB, et al: miR-155 promotes FLT3-ITD-induced myeloproliferative disease through inhibition of the interferon response. Blood 129: 3074-3086, 2017.

23. Liu ZL, Wang H, Liu J and Wang ZX: MicroRNA-21 (miR-21) expression promotes growth, metastasis, and chemo- or radioresistance in non-small cell lung cancer cells by targeting PTEN. Mol Cell Biochem 372: 35-45, 2013.

24. Zhu Y, Han Y, Tian T, Su P, Jin G, Chen J and Cao Y: MiR-21-5p, miR-34a, and human telomerase RNA component as surrogate markers for cervical cancer progression. Pathol Res Pract 214: 374-379, 2018.

25. Okugawa Y, Yao L, Toiyama Y, Yamamoto A, Shigemori T, Yin C, Omura Y, Ide S, Kitajima T, Shimura T, et al: Prognostic impact of sarcopenia and its correlation with circulating miR-21 in colorectal cancer patients. Oncol Rep 39: 1555-1564, 2018

26. Chen S, Chen X, Shan T, Ma J, Lin W, Li W and Kang Y: MiR-21-mediated Metabolic Alteration of Cancer-associated Fibroblasts and Its Effect on Pancreatic Cancer Cell Behavior. Int J Biol Sci 14: 100-110, 2018.

27. Luo F, Ji J, Liu Y, Xu Y, Zheng G, Jing J, Wang B, Xu W, Shi L, Lu X, et al: MicroRNA-21, up-regulated by arsenite, directs the epithelial-mesenchymal transition and enhances the invasive potential of transformed human bronchial epithelial cells by targeting PDCD4. Toxicol Lett 232: 301-309, 2015.

28. Yang Q, Xu E, Dai J, Wu J, Zhang S, Peng B and Jiang Y: miR-21 regulates $\mathrm{N}$-methyl-N-nitro-N'-nitrosoguanidine-induced gastric tumorigenesis by targeting FASLG and BTG2. Toxicol Lett 228 : $147-156,2014$

29. Wang G, Wang JJ, Tang HM and To SS: Targeting strategies on miRNA-21 and PDCD4 for glioblastoma. Arch Biochem Biophys 580: 64-74, 2015.

30. Fu X, Han Y, Wu Y, Zhu X, Lu X, Mao F, Wang X, He X, Zhao $Y$ and Zhao Y: Prognostic role of microRNA-21 in various carcinomas: A systematic review and meta-analysis. Eur J Clin Invest 41: 1245-1253, 2011.

31. Asangani IA, Rasheed SAK, Nikolova DA, Leupold JH, Colburn NH, Post S and Allgayer H: MicroRNA-21 (miR-21) post-transcriptionally downregulates tumor suppressor Pdcd 4 and stimulates invasion, intravasation and metastasis in colorectal cancer. Oncogene 27: 2128-2136, 2008

32. Espadinha AS, Prouzet-Mauléon V, Claverol S, Lagarde V, Bonneu M, Mahon FX and Cardinaud B: A tyrosine kinase-STAT5-miR21-PDCD4 regulatory axis in chronic and acute myeloid leukemia cells. Oncotarget 8: 76174-76188, 2017.

33. Ruiz-Lafuente N, Alcaraz-Garcia MJ, Sebastian-Ruiz S García-SernaAM, Gómez-Espuch J, Moraleda JM, Minguela A, García-Alonso AM and Parrado A: IL-4 up-regulates MiR-21 and the MiRNAs hosted in the CLCN5 gene in chronic lymphocytic leukemia. Plos One 10: e0124936, 2015.

34. Taverna S, Giallombardo M, Pucci M, Flugy A, Manno M, Raccosta S, Rolfo C, De Leo G and Alessandro R: Curcumin inhibits in vitro and in vivo chronic myelogenous leukemia cells growth: A possible role for exosomal disposal of miR-21. Oncotarget 6: 21918-21933, 2015.

35. Labib HA, Elantouny NG, Ibrahim NF and Alnagar AA: Upregulation of microRNA-21 is a poor prognostic marker in patients with childhood B cell acute lymphoblastic leukemia. Hematology 22: 392-397, 2017.

36. Riccioni R, Lulli V, Castelli G, Biffoni M, Tiberio R, Pelosi E, Lo-Coco F and Testa U: miR-21 is overexpressed in NPM1-mutant acute myeloid leukemias. Leuk Res 39: 221-228, 2015.

37. Liu P, Li P and Burke S: Critical roles of Bcl11b in T-cell development and maintenance of T-cell identity. Immunol Rev 238: $138-149,2010$

38. Wakabayashi Y, Inoue J, Takahashi Y, Matsuki A, Kosugi-Okano H,Shinbo T, Mishima Y, Niwa O and Kominami R: Homozygous deletions and point mutations of the Rit1/Bcl11b gene in gamma-ray induced mouse thymic lymphomas. Biochem Biophys Res Commun 301: 598-603, 2003.

39. Abbas S, Sanders MA,Zeilemaker A, Geertsma-Kleinekoort WM, Koenders JE, Kavelaars FG, Abbas ZG, Mahamoud S, Chu IW, Hoogenboezem R, et al: Integrated genome-wide genotyping and gene expression profiling reveals BCL11B as a putative oncogene in acute myeloid leukemia with $14 \mathrm{q} 32$ aberrations. Haematologica 99: 848-857, 2014

40. Landgraf P, Rusu M, Sheridan R, Sewer A, Iovino N, Aravin A, Pfeffer S, Rice A, Kamphorst AO, Landthaler M, et al: A mammalian microRNA expression atlas based on small RNA library sequencing. Cell 129: 1401-1414, 2007.
41. National Cancer Institute: The Cancer Genome Atlas Program. Accessed from: http://cancergenome.nih.gov/publications/publicationguidelines.

42. Livak KJ and Schmittgen TD: Analysis of relative gene expression data using real-time quantitative PCR and the $2(-\Delta \Delta C(T))$ method. Methods 25: 402-408, 2001

43. Morris GF and Mathews MB: Regulation of proliferating cell nuclear antigen during the cell cycle. J Biol Chem 264: 13856-13864, 1989.

44. Zhong W, Peng J, He H, Wu D, Han Z, Bi X and Dai Q: Ki-67 and PCNA expression in prostate cancer and benign prostatic hyperplasia. Clin Invest Med 31: E8-E15, 2008

45. Juríková M, Danihel L, Polák S and Varga I: Ki67, PCNA, and MCM proteins: Markers of proliferation in the diagnosis of breast cancer. Acta Histochem 118: 544-552, 2016.

46. Kimos MC, Wang S, Borkowski A, Yang GY, Yang CS, Perry K, Olaru A, Deacu E, Sterian A, Cottrell J, et al: Esophagin and proliferating cell nuclear antigen (PCNA) are biomarkers of human esophageal neoplastic progression. Int J Cancer 111: 415-417, 2004

47. Obata M, Kominami R and Mishima Y: BCL11B tumor suppressor inhibits HDM2 expression in a p53-dependent manner. Cell Signal 24: 1047-1052, 2012.

48. Li Y, Li W, Yang Y, Lu Y, He C, Hu G, Liu H, Chen J, He J and Yu H: MicroRNA-21 targets LRRFIP1 and contributes to VM-26 resistance in glioblastoma multiforme. Brain Res 1286: 13-18, 2009.

49. Li T, Li D, Sha J, Sun P and Huang Y: MicroRNA-21 directly targets MARCKS and promotes apoptosis resistance and invasion in prostate cancer cells. Biochem Biophys Res Commun 383 280-285, 2009

50. Kimura S, Naganuma S, Susuki D, Hirono Y, Yamaguchi A, Fujieda S, Sano K and Itoh H: Expression of microRNAs in squamous cell carcinoma of human head and neck and the esophagus: MiR-205 and miR-21 are specific markers for HNSCC and ESCC. Oncol Rep 23: 1625-1633, 2010.

51. Volinia S, Galasso M, Costinean S, Tagliavini L, Gamberoni G, Drusco A, Marchesini J,Mascellani N, Sana ME, Abu JarourR, et al: Reprogramming of miRNA networks in cancer and leukemia. Genome Res 20: 589-599, 2010.

52. Pichiorri F, Suh SS, Ladetto M, Kuehl M, Palumbo T, Drandi D, Taccioli C, Zanesi N, Alder H, Hagan JP, et al: MicroRNAs regulate critical genes associated with multiple myeloma pathogenesis. Proc Natl Acad Sci USA 105: 12885-12890, 2008.

53. Fulci V, Chiaretti S, Goldoni M, Azzalin G, Carucci N, Tavolaro S, Castellano L, Magrelli A, Citarella F, Messina M, et al: Quantitative technologies establish a novel microRNA profile of chronic lymphocytic leukemia. Blood 109: 4944-4951, 2007.

54. Asangani IA, Rasheed SAK, Nikolova DA, Leupold JH, Colburn NH, Post S and Allgayer H: MicroRNA-21 (miR-21) post-transcriptionally downregulates tumor suppressor Pdcd4 and stimulates invasion, intravasation and metastasis in colorectal cancer. Oncogene 27: 2128-2136, 2008.

55. He C, Dong X, Zhai B, Jiang X, Dong D, Li B, Jiang H, Xu S and Sun X: MiR-21 mediates sorafenib resistance of hepatocellular carcinoma cells by inhibiting autophagy via the PTEN/Akt pathway. Oncotarget 6: 28867-28881, 2015.

56. Lee BS, Dekker JD, Lee BK, Iyer VR, Sleckman BP, Shaffer AL III, Ippolito GC and Tucker PW: The BCL11A transcription factor directly activates RAG gene expression and V(D) J recombination. Mol Cell Biol 33: 1768-1781, 2013.

57. Cismasiu VB, Adamo K, Gecewicz J, Duque J, Lin Q and Avram D: BCL11B functionally associates with the NuRD complex in $\mathrm{T}$ lymphocytes to repress targeted promoter. Oncogene 24 . 6753-6764, 2005

58. Wu H,Pomeroy SL, Ferreira M, Teider N, Mariani J, Nakayama KI, Hatakeyama S, Tron VA, Saltibus LF, Spyracopoulos L, et al: UBE4B promotes Hdm2-mediated degradation of the tumor suppressor p53. Nat Med 17: 347-355, 2011.

59. Kubbutat MH, Jones SN and Vousden KH: Regulation of p53 stability by Mdm2. Nature 387: 299-303, 1997.

60. Go R, Takizawa K, Hirose S, Katsuragi Y, Aoyagi Y, Mishima Y and Kominami R: Impairment in differentiation and cell cycle of thymocytes by loss of a Bcl11b tumor suppressor allele that contributes to leukemogenesis. Leuk Res 36: 1035-1040, 2012.

61. Kamimura K, Mishima Y, Obata M, Endo T, Aoyagi Y and Kominami R: Lack of Bcl11b tumor suppressor results in vulnerability to DNA replication stress and damages. Oncogene 26: 5840-5850, 2007 